\title{
LA EXPLOSIÓN DE UN PARADIGMA
}

\section{THE EXPLOSION OF A PARADIGM}

Jesús Delgado Delgado: Asociación de GNU/Linux Lilo-Gulalcarria. Madrid (España).

jesus.delgado@ozu.es

\section{CURRÍCULUM VITAE}

Programador y Miembro de la Asociación de GNU/Linux Lilo-Gulalcarria. Es uno de los desarrolladores del sistema operativo LINUX más destacados de habla hispana. Autor de trabajos especializados en dicho sistema operativo y experto en computación.

\section{RESUMEN}

La historia de la informática, y más en concreto la doméstica, ha tenido un avance espectacular en muy pocos años. Un tiempo en el que hemos pasado de mostruosos ordenadores que nacieron para ejecutar juegos en un principio, de precio astronómico y memoria mínima, a unas máquinas de mínima ocupación y enorme potencia, con una memoria gigante $\mathrm{y}$, por supuesto, a un precio más asequible. Con este cambio llegaron los sistemas operativos que compiten con Microsoft. GNU/LINUX es uno de ellos. De una gran calidad, buenas prestaciones, fácil de instalar y actualizar, su principal ventaja es que el código de fuente, y por tanto el control de lo que realmente hace ese sistema operativo, está libremente disponible para los usuarios y son ellos mismos los que lo han ido desarrollando, según sus intereses, a lo largo del tiempo. 


\title{
PALABRAS CLAVE
}

Informática doméstica - ordenadores - sistema operativo - GNU/LINUX

\begin{abstract}
The history of computing, and specifically domestic violence, has taken a quantum leap in few years. A time when monsters have passed from computers that were born to run games at first astronomical price and minimum memory to a minimum occupation machines and enormous power, with a huge memory and, of course, a more affordable price. With this change came competing operating systems to Microsoft. GNU / Linux is one of them. Of high quality, good performance, easy to install and upgrade, its main advantage is that the source code, and therefore control what really makes this operating system is freely available to users and that they themselves have been developed, according to their interests over time.
\end{abstract}

\section{KEY WORDS}

Home computing - computers - operating system - GNU/LINUX

\section{TEXTO:}

La historia de la informática es corta. La de la informática doméstica lo es mucho más. O larga, según se mire, como largo ha sido el trayecto recorrido... Es muy difícil encontrar otro aspecto de la tecnología, o de la ciencia en general, que haya tenido tan espectaculares avances como la informática doméstica en tan pocos años. 
Los algo más viejos recordamos los primeros PC's domésticos, (ZX81, Spectrum, Commodore, Amstrad...) nacidos para ejecutar juegos contenidos en cintas de cassete, que se disfrutaban a través de la televisión, a duras penas programables por su cortísima memoria y a duras penas adquiribles por su alto coste; los más tenemos, asimismo, en la memoria, aquellas otras máquinas, ordenadores de sobremesa propiamente dichos, que ya servían para otras cosas además de para jugar, de astronómico precio, abultado volumen y memoria enana, que era necesario arrancar con un disco que contenía el sistema operativo. ¡Claro, el sistema operativo MS-DOS de Microsoft!

¡Qué tiempos aquellos! ¿Ves cómo la historia parece larga? Ahora poseemos máquinas de una potencia entonces insospechada, con una memoria gigante, unos discos de almacenamiento monstruosos y a precios más bajos; los niños los utilizan con soltura indiscutible y hablan de sus megas y de sus gigas como de cromos o de muñecos. Pero en el fondo, sin embargo, sigue permaneciendo como necesario el Sistema Operativo, aunque ya no es el DOS, ni resulta imprescindible que sea de Microsoft. ¡Sí!; no mires así... Hay otros sistemas operativos alternativos que compiten con el de Microsoft, con Windows para entendernos, y alguno es, bajo mi punto de vista y, a pesar de los anuncios de la marca, bastante mejor y más barato. Tan barato que no cuesta nada. Me estoy refiriendo, concretamente, a GNU/LINUX.

¿Qué es GNU/Linux? GNU/Linux es un sistema operativo de la más alta calidad y prestaciones, fácil de instalar y de actualizar. Tan sistema operativo como Ms-Dos o Windows, pero con una gran diferencia: el código fuente -y por tanto el control de lo que realmente hace ese sistema operativo- está libremente disponible para los usuarios. Además, no tiene propietarios que nos puedan obligar, de una u otra forma, a satisfacer sus intereses económicos (compra de nuevas actualizaciones) y comerciales (utilización de aplicaciones insufribles y/o poco prácticas que no interesan a los usuarios, por mucho que sí interesen al dueño del sistema operativo). 
El desarrollo de GNU/Linux se hace, además, con el concurso de miles de usuarios y profesionales de todo el mundo y todos los que desarrollan aplicaciones para este sistema operativo saben que lo que prima es la calidad del producto y no los intereses particulares. ¿Bonito, no?

Según esto, entonces, en los sistemas propietarios te venden algo definido por un precio, pero no te dan capacidad de modificación sustancial, y después, tras un tiempo de uso útil que depende en gran medida del mismo propietario, has de actualizar el producto, ya inservible, volviendo a desembolsar tu dinero. GNU/LINUX se puede obtener gratuitamente a través de Internet en numerosas distribuciones que, con apariencias diferentes, mantienen un mismo "corazón" del sistema. Por añadidura, hemos visto que una parte de los usuarios de GNU/LINUX, los más virtuosos, está constantemente perfeccionando el sistema, por lo que la actualización constante y rápida se garantiza de forma imparable. Eligiendo una determinada "distribución" (la que más te guste), tendrás siempre tu sistema operativo actualizado, sin efectuar desembolso alguno. ¡Oye... que es cierto... que puedes tener gratis un BUEN sistema operativo!

Sí. Ya veo. Quieres enterarte de algo más de GNU/LINUX. De cómo nació, de quién lo creó, de, en fin, sus diferencias principales con otros sistemas... Vamos a ello. Linux deviene de UNIX, del que habrás oído hablar porque es un excelente sistema operativo muy utilizado en grandes computadoras. En 1991 Linux Torvalds, un estudiante de la Universidad de Helsinki, comenzó a desarrollar como hobbie, un sistema abreviado de Unix que, pasado el tiempo y tras muchos avatares, terminó en 1994 en un núcleo definido (kernel), versión 1.0. Desde esta fecha no ha parado el desarrollo y hoy podemos afirmar que dispone de todas las prestaciones de un UNIX moderno: multitarea real, memoria virtual, bibliotecas compartidas, control de carga de sistema bajo demanda, compartición de recursos, buen manejo de memoria, 
soporte de redes TCP/IP... Este núcleo está acompañado de multitud de programas (www.gnu.org), de ahí su nombre GNU/Linux.

¡Ah! Se me olvidaba. La mascota de LINUX es TUX, un simpático pingüino. Todo, incluido el pingüino, sin desembolso, gratis, créeme. El núcleo de GNU/LINUX (kernel) puede ser copiado libremente y también es posible modificarlo y distribuirlo, dejando siempre disponible para los demás el código fuente. En fin, puedes utilizarlo sin restricciones y, si eres capaz, cambiarlo en la medida que tu saber y necesidades lo aconsejen. Tienes para ello, además, el apoyo de todos los usuarios de GNU/LINUX del mundo mundial. Varias universidades, por ejemplo, lo utilizan para sus clases. LINUX es, además, de software libre y código abierto, GNU y GPL, es decir, de distribución libre y gratuita y de código fuente necesariamente abierto y público. Pero de estos y otros entresijos ya te enterarás más tarde...

Me preguntas si es bueno. Gran cuestión... ¿Conoces Windows? Pues GNU/LINUX es aparentemente igual a la vista pero... tiene grandes diferencias interiores. Te resumo a continuación sus características.

\section{Características de GNU/LINUX}

- Se distribuye su código fuente, es decir, cualquier persona puede hacer todos los cambios necesarios para resolver sus problemas de funcionalidad, con el único requisito de ponerlos a disposición general.

-Su desarrollado es abierto, interviniendo en él miles de usuarios distribuidos por todo el mundo, lo que permite un rapidísimo y eficiente ciclo de desarrollo. No depende, por añadidura, de empresa o corporación alguna. 
- Cuenta con un amplio y robusto soporte para comunicaciones y redes, por lo que puede ser utilizado tanto por particulares como por empresas.

- Interfaz de usuario o Shell personalizable. Los usuarios pueden "hacerse" sus shells conforme a sus gustos y conveniencias, adecuándolas a sus propias necesidades específicas y convirtiéndolas en entornos operativos controlables.

- Es Multitarea: Con Linux se pueden ejecutar varios programas a la vez sin que hayan de pararse unas aplicaciones para la ejecución de otras.

- Es Multiusuario: Permite compartir recursos con facilidad y hace posible que varios usuarios puedan trabajar al mismo tiempo a través de terminales distintos ya sobre aplicaciones diferentes, ya sobre un mismo programa.

- Es integralmente Seguro: El concepto de seguridad en el campo de la informática es siempre relativo. Con esta prevención, puede decirse claramente que GNU/LINUX es un sistema razonablemente seguro para albergar datos confidenciales, a salvo de los hackers e intrusos, por la seguridad de sus contraseñas de acceso a usuarios y sus cortafuegos, para mantenerlos, no se "cuelga" ni se desconfigura fácilmente y para conservarlos a salvo de virus y otros ataques análogos, ya que lo impide su concepción nucleica.

- Controla adecuadamente los Dispositivos: Los controladores son tratados de forma independiente al núcleo del sistema y se pueden instalar tantos controladores como dispositivos nuevos se vayan añadiendo al ordenador.

- Redes de Ordenadores: Mediante GNU/LINUX puedes disponer de múltiples aplicaciones de libre distribución que permiten navegar por Internet y enviar y recibir correo electrónico. Tiene, por añadidura, una gran variedad de comandos 
para comunicarse internamente entre usuarios ubicados en plataformas distintas. Un universo de posibilidades de comunicación, en resumen, pueden ser recopiladas de las aplicaciones escritas para GNU/Linux en los más variados formatos, con diferente dificultad de instalación, mantenimiento y objetivos.

¿Tú conoces un sistema operativo mejor, más barato y más actualizado? Pues si no es así, instala GNU/LINUX. Pruébalo y, al igual que nos ha pasado a los demás, te verás gratamente sorprendido. Aunque dudes en este momento, prueba, para lo que te va a costar... Hace tiempo que ya no se asocia el concepto de "sistema operativo" solamente con Windows o con la firma Microsoft, y eso es bueno para la competitividad, la superación de los productos y los bolsillos. Hace tiempo que ese paradigma explotó porque la realidad le hizo explotar. Ahora puedes comprobarlo. 